\title{
Bicyclist's vulva: observational study
}

Luc Baeyens, Elke Vermeersch, Pierre Bourgeois

Sports Gynaecology Unit, Brugmann University Hospital, Belgium

Luc Baeyens

professor and head of the department of gynaecology

Elke Vermeersch resident in gynaecology and obstetrics

Department of Radioisotopes, Institut J Bordet, B-1000 Brussels Pierre Bourgeois head of nuclear medicine

Correspondence to: L Baeyen

luc.baeyens@

chu-brugmann.be

BMJ 2002;325:138-9 B-1020 Brussels,

Many chronic injuries related to athletic bicycling are now recognised: cyclist's nipples, ${ }^{1}$ neuropathic syndromes, ${ }^{2}$ and skin problems caused by the saddle. We have seen a new clinical problem in female high level cycling competitors: bicyclist's vulva (figure)

\section{Participants, methods, and results}

Six women, aged 21-38 years, had a unilateral chronic swelling of the labium majus after a few years of intensive bicycling (an average of $462.5 \mathrm{~km}$ per week). All six had typical unilateral lymphoedema (five on the right side, one on the left) which was more severe after more intense and longer training. The position of the bicycle saddle, the type of shorts worn, and the women's perineal hygiene were optimum. There was no family history of lymphoedema in any of the women, nor any common factor that might explain the lymphoedema.

All six women regularly had inflammatory skin problems related to the saddle and five had scars and perineal lesions such as chafing, perineal folliculitis, and nodules. Further clinical and ultrasound examination showed no pelvic anomaly.

Three of the cyclists (aged 27, 21, and 21 years) underwent three phase lymphoscintigraphy of their legs. ${ }^{3}$ We found similar lymphatic anomalies in all three. One had bilateral intra-abdominal abnormalities at the level of the iliac nodes and functional insufficiency of the superficial lymphatic system on the left side, the same side as the oedematous labium majus. In the other two, who presented with oedema of the right labium majus, lymphoscintigrams showed decreased uptake at the height of the right lumboaortic nodes. One of these two also had some inguinal nodes in the right groin. A previous study found no lymphatic abnormalities in the general population. ${ }^{3}$

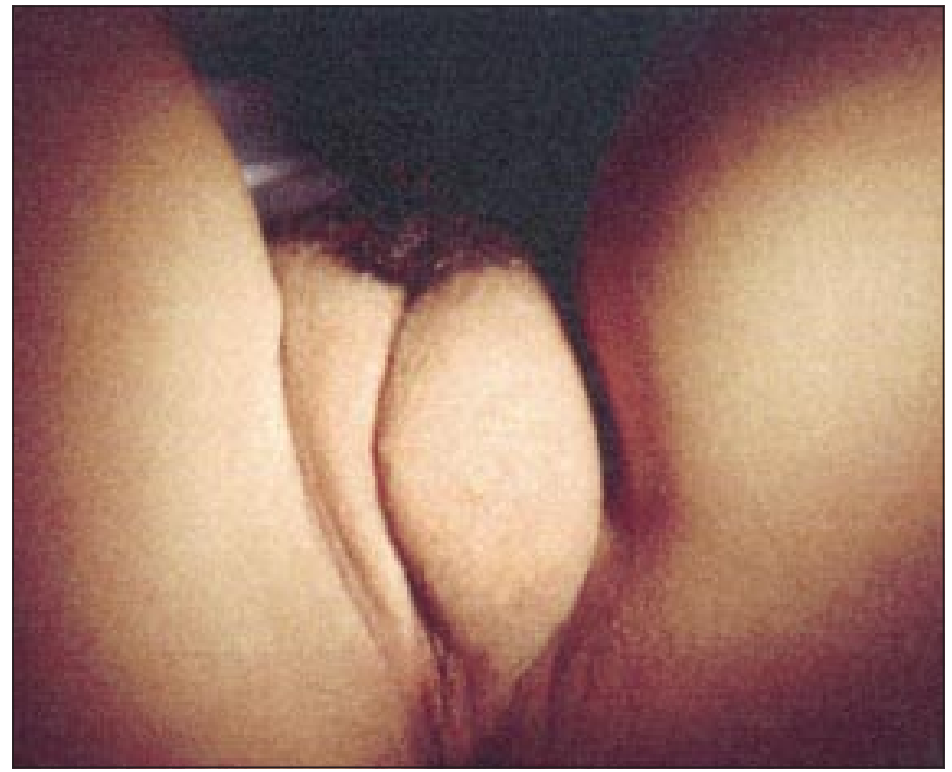

Bicyclist's vulva
Two women (aged 23 and 38 years) refused lymphoscintigraphy for personal reasons. The fifth woman (aged 34 years) was not offered the procedure owing to a history of pelvic surgery for endofibrosis of the external iliac artery, a syndrome seen in high level competition cyclists. ${ }^{4}$ In this patient, unilateral lymphoedema of the vulva was present before vascular surgery and resolved only partially after the vascular intervention. None of the other five cyclists presented symptoms of this vascular compression syndrome.

\section{Comment}

Cyclists with unilateral chronic swelling of the labium majus had similar lymphoscintigraphic abnormalities in their pelvis and homolateral leg.

Vulvar lymphoedema may be caused by a combination of chronic inflammation in the vulvoperineal area-very common in competitive cyclists-with damage to lymphatic vessels and repeated compression of the inguinal lymphatic vessels due to the curved posture of the cyclists. Both of these factors could contribute to alterations in lymphatic circulation in the vulvoperineal area. The abnormalities seen by lymphoscintigraphy might ultimately lead to more generalised lymphoedema of the legs.

We have yet to conduct prospective lymphoscintigraphic studies in a random sample of competitive cyclists. It is possible, in these women, that lymphatic disease existed before (latent lymphoedema) but was exposed by their intensive bicycling. The lymph nodes can be abnormal in lymphoedema praecox (affecting patients 2 to 35 years old) and tarda (affecting patients older than 35 years old).

In addition to standard measures for preventing saddle lesions, ${ }^{2}$ we recommend thorough care of any lesion of the vulvoperineal region. Elevation of the lower limbs during rest periods contributes to a better lymph drainage of the perineum and pelvis. Oedema may be reduced by applying cold compresses on the vulvoperineal region after training and by physiotherapy that stimulates alternative lymph drainage pathways. $^{5}$

We thank Monique Van Noten for secretarial assistance.

Contributors: $\mathrm{LB}$ discovered the first case. The other women were seen by LB and EV. PB, carried out the lymphoscintigraphies, assisted by LB and EV. LB, EV, and PB wrote the paper.

Funding: No additional funding.

Competing interests: None declared.

Powell B. Bicyclist's nipples. JAMA 1983;249:2457.

2 Mellion MB. Common cycling injuries: management and prevention. Sports Med 1991;11:52-70.

Bourgeois P, Munck D, Becker C, Leduc O, Leduc A. A three-phase lymphoscintigraphic investigation protocol for the evaluation of lower limb edemas. Eur J Lymphol 1997;6:10-21.

4 Abraham P, Saumet JL, Chevalier JM. External iliac artery endofibrosis in athletes. Sports Med 1997;24:221-6.

5 Rubin JR, Eberlin LB. The effect of inguinal lymphatic manipulation on regional lymph flow patterns. J Vasc Surg 1993;17:896-900.

(Accepted 30 January 2002) 


\section{Commentary: Attitudes to women's bicycling have changed}

The typical female cyclist in the United Kingdom is unlikely to be clocking up an average $462.5 \mathrm{~km}$ per week. For most of us, the risk of serious harm from contact between body and bike is probably insignificant compared with that arising from contact between bike and motor vehicle (hence the emergence of the leisure cycle trails, accessed largely by car).

In 2002, the report of a form of vulval damage, possibly caused or exacerbated by intensive bicycling training, and possibly implicated in more extensive lymphatic disease, seems unlikely to generate wide scale public debate about the desirability of women engaging in cycling in general. Nor do the authors themselves raise concerns about whether high level competitive cycling is a suitable activity for women. Their affiliation to a sport gynaecology clinic is an expression of the institutionalisation of competitive sports for women by the beginning of the 21st century. The risks to women of such participation are seen as warranting special surveillance and expert management but not as grounds for women's exclusion from high level competition.

The same report a century ago might have taken a different view. In the late 19th century, the coming of the (relatively) cheap safety bicycle revolutionised personal transport and recreation for people of all ages and classes and of both sexes. By the 1890s, the sight of large numbers of women pedalling freely was "a sign of dramatically changing times." To some, this "new woman" on the roads conveyed a welcome image of female vitality and independence, with its encouragement of more rational dress and reduced chaperonage. (In 1904, the women students of Girton College, Cambridge, were permitted to ride to lectures after dark, unaccompanied by a don, if in groups of at least three. $\left.{ }^{1}\right)$ For others, women's passion for cycling was more like a harbinger of doom for the imperial race, through the deleterious impact of excessive strain and jolting on women's reproductive systems.

The medical profession, not surprisingly, expressed its views on this matter in the $B M J$ and elsewhere; views which were, by no means, all hostile. According to Dr W $\mathrm{H}$ Fenton, when women began bicycling, there was much "solemn wagging of grey beards and a low pitched murmur of 'grave consequences' to be anticipated" from doctors, particularly those too old and too conscious of their dignity to have actually tried bicycling. ${ }^{2}$ But, by 1896 , with improvements to bicycles and some years of the experiment, Fenton opined confidently, "an organically sound woman can cycle with as much impunity as a man." If women "cycle on commonsense terms for pleasure and health, the sex and the community at large will greatly benefit, and all prejudices will be assuredly overcome."' Most doctors' support was conditional on women's exercise of commonsense, most having "wisely set their faces against racing and record breaking. Both are physiological crimes."' The Cycle Touring Club of Great Britain admitted women as full members from 1880 , but the club refused to allow women's racing, on grounds of propriety and female physiology for several decades. Women's bicycling for pleasure or for convenience, for improving their fitness to be mothers, it seems, was one thing; taking it seriously, behaving competitively, training their bodies, as if they were men, was quite another.

1 McCrone KE. Sport and the physical emancipation of English women, 1870-1914. London: Routledge, 1988:183.

2 Fenton WH. A medical view of cycling for ladies. The Nineteenth Century 1896;39:799-800
Department of Social and Political Science, Royal Holloway College, University of London, Egham TW20 0EX

Mary Ann Elston senior lecturer m.elston@rhul.ac.uk

\section{A memorable patient Swimming the water of life}

At the age of 35 , I started swimming lessons to be able to accompany my children into the pool. I met Alfred at my first lesson. He looked about 70 then. I watched him walk slowly and painstakingly with his tripod. As I stood at the steps of the pool behind him, he nodded and said, "After you, doctor."

"Oh. Have we met before?" I asked. Alfred introduced himself. He had been a patient on our stroke ward more than four years back. He had had a severe stroke and had to be ventilated for a few weeks. He had made a remarkable recovery after about eight months' rehabilitation. As he told me all the details, I remembered him and how determined he had been to get well. He had worked very hard with the rehabilitation team. I was pleased to see how well he looked.

He loved swimming. He had been a good swimmer in his younger days and had started swimming again three years after his stroke. He thought it improved his balance and his stamina. The instructors helped him. He lived on his own, having lost his wife 10 years before. The swimming lesson was a social event for him: he knew everyone and, with a cheerful smile, chatted away to all. He always had a kind word for me when I felt discouraged by my lack of progress in swimming.

On one of our chats he told me that he did not want to have another stroke as he had no children or close family. His kind neighbour brought him for his swimming lesson every week. He went to the shops with his scooter and was fairly independent. He did not want to be a burden to anyone.

Months went by, and Alfred's swimming improved. We all felt happy for him. He started doing charity swims for the multiple sclerosis and epilepsy societies. His name appeared in the local newspaper. He mentioned to me from time to time how grateful he felt to all the members of the stroke team. His next charity swim would be for the stroke unit.

One cold January morning I arrived early for the swimming lesson. As I waited, other pupils for the lesson arrived, but Alfred did not come. I felt uneasy; he hardly ever missed his lesson. He was planning a sponsored swim of a mile for the stroke unit and had generous sponsors.

As we entered the pool, I asked our instructor. Alfred had been found dead in bed four days previously, he told me. I was stunned, and my heart felt as heavy as lead.

Had Alfred done too much, I wondered. But at least he did what he loved and was happy doing it. The lessons were not the same without his cheerful smile. His enthusiasm, optimism, and zest for life had made a lasting impression on my mind. And I was grateful that God had listened to his prayer and that he had died without being a burden to anyone.

Shubhada Suri staff grade physician, Rotherham 